\title{
PLANOS DIRETORES MUNICIPAIS: AVALIAÇÃO DE INSTRUMENTOS SEGUNDO PRINCÍPIOS DO ESTATUTO DA CIDADE
MUNICIPAL GUIDING PLANS: EVALUATION OF INSTRUMENTS ACCORDING TO PRINCIPLES OF THE CITY STATUTE

\author{
Danaê Fernandes', Ana Letícia Gonçalves², Ideni T. Antonello', Milena Kanashiro \\ ${ }^{1}$ Universidade Estadual de Londrina (UEL), Londrina, PR, Brasil \\ 'Instituto de Tecnologia Desenvolvimento Econômico Social (ITEDES), Londrina, PR, Brasil
}

Correspondência para: Danaê Fernandes (daenandes@gmail.com)

doi: 10.12957/geouerj.2018.33716

Recebido em: 06 abr. 2018 | Aceito em: 15 mai. 2018

\section{SANTOS JUNIOR, O. A dos; MONTANDON, D. T. (orgs.). Planos diretores municipais pós estatuto da cidade: balanço crítico e perspectivas. RJ: Letra Capital: Observatório das Cidades: IPPUR/UFRJ, 2011.}

O trabalho organizado por Orlando Alves dos Santos Junior e Daniel Todtmann Montandon é uma compilação de resultados acerca da análise de 526 Planos Diretores Municipais (PDMs), cuja estratégia de ação foi coordenada pelo Ministério das Cidades, via Secretaria Nacional de Programas Urbanos e Universidade Estadual do Rio de Janeiro.

Foram analisados cerca de um terço dos municípios brasileiros com obrigatoriedade de elaboração de PDM, determinada pelo Estatuto da Cidade (Lei Federal $n^{\circ} 10.257 / 2001$ ). Todos os PDMs escolhidos foram aprovados após a promulgação do Estatuto, obedecendo critérios de distribuição populacional, de forma a considerar os diferentes portes e tipologias de municípios de todos os estados do país.

As avaliações dos PDM selecionados utilizaram como roteiro uma metodologia comum, utilizada por uma rede de pesquisadores para verificar a autoaplicabilidade dos instrumentos, de forma a compor 27 relatórios estaduais e 26 relatórios de estudo de caso, que, por sua vez, culminaram na elaboração de um relatório nacional. Com essa aferição qualitativa, formou-se um balanço geral capaz de indicar o estado da arte do processo de elaboração dos PDM no Brasil após o Estatuto da Cidade. 
O trabalho foi apresentado em eixos temáticos, dos quais fizeram parte: questões habitacionais, ambientais e metropolitanas, acesso à terra urbanizada, mobilidade e transporte, e planejamento participativo.

Sobre incorporação dos instrumentos do acesso à terra urbanizada previstos no estatuto da cidade nos PDM, foi notado grande crescimento do instrumento de zonas de habitação de interesse social (ZEIS) entre os anos de 2001 a 2009, assim como a expressiva presença de zoneamento ou macrozoneamento, edificação ou utilização compulsórios, IPTU progressivo no tempo e desapropriação. Entretanto, foi notada generalizada inadequação da regulamentação de instrumentos para sua efetiva aplicação, com precariedade no rebatimento territorial das diretrizes e instrumentos estabelecidos. Mesmo que exista a presença de ferramentas de acesso à terra, a autoaplicabilidade e efetividade dessas ferramentas são comprometidas, principalmente quanto à indução do desenvolvimento urbano, por falhas na regulamentação e demarcação adequada no território. Na prática, são percebidas contradições entre leis de parcelamento e uso e ocupação do solo e os respectivos PDM, além de lacunas em geoprocessamento e cadastro territorial multifinalitário.

Semelhante conclusão se estende à questão habitacional nos PDM. Embora haja incorporação de elementos relacionados à política de habitação, não são dadas todas as condições necessárias para a efetividade dos instrumentos.

Em linhas gerais, poucos incorporam programas específicos para moradia popular, como urbanização de favelas, regularização de loteamentos, etc. Quando incorporados, o foco é a provisão habitacional, regularização urbanística, criação de banco de terras e reservas fundiárias nos processos de parcelamento do solo. Há pouca referência à aplicação de IPTU progressivo, parcelamento compulsório e outorga onerosa do direito de construir voltados para a finalidade de habitação de interesse social. Também foi notada a inexistência de articulação entre política Habitacional e orçamento municipal, denotando falta de prioridade na superação dos problemas habitacionais do município. Em síntese, grande parte dos PDM apresenta ZEIS, mas somente metade demarca esse instrumento em mapa, necessitando de detalhamentos e regulamentações posteriores. De acordo com 
os autores, os relatórios registram que, nos seus respectivos estados, o crescimento urbano não vem acompanhado necessariamente de melhoria na qualidade de vida das pessoas, mas, ao contrário, acentua carências e discrepâncias habitacionais, evidenciando a segregação socioespacial. Como pontos positivos, destaque para alguns municípios que usaram concessão de uso especial para fins de moradia, direito de superfície e direito de preempção, ZEIS em áreas vazias, e vinculação de recursos de outorga onerosa à produção de habitação de interesse social, no sentido de se criar um fundo municipal de habitação, que poderia se fomentado com os recursos obtidos com esses instrumentos, tendo em vista $o$ seu caráter de extrafiscalidade.

Na questão do saneamento ambiental, há esforços no sentido de ampliar as infraestruturas sanitárias e a preservação de recursos naturais. No geral, são constatadas deficiências no abastecimento de água e no esgotamento sanitário, cuja estratégia de melhoria não é constante nos PDM. Por vezes, políticas de uso do solo, habitação de interesse social e expansão urbana conflitam com a infraestrutura de drenagem, água potável e esgoto, culminando em fragilidades para ampliação do acesso aos serviços de saneamento básico. As questões ambientais são tratadas de forma heterogênea nos PDM e, de modo geral, não partem da análise ambiental para estruturação do território.

É notado que poucos municípios incorporam mecanismos ou instrumentos efetivos para orientar o crescimento urbano de forma a minimizar os impactos ambientais. Assim, mesmo quando o discurso de sustentabilidade encontra-se presente, não há meios disponíveis nos PDM para a concretude da política ambiental, já que não há abordagem integrada da questão ambiental com as demais políticas setoriais, nem mecanismos efetivos de articulação. Há prevalência da tradição preservacionista na questão ambiental, porém com grandes contradições entre a abordagem urbana e a abordagem ambiental.

Considera-se uma baixa incorporação de licenciamento ambiental nos PDM que, por outro lado, apresentam o estudo de impacto de vizinhança (EIV) como instrumento mais frequente. Mesmo assim, o EIV é tratado de forma pouco delineada, sem detalhamento ou vínculo com políticas concretas de meio ambiente. 
No que se refere à mobilidade urbana e transporte, percebeu-se avanço na perspectiva de incorporar a política de mobilidade urbana como instrumento de universalização do direito à cidade, porém, sem instrumentos autoaplicáveis nem definição de metas e diretrizes para alocação de recursos. Existe grande ênfase no planejamento do sistema viário, com caracterização de hierarquia de vias que, tradicionalmente, estabelecem diretrizes para expansão e adequação do sistema viário considerando apenas os deslocamentos dos veículos, e não os das pessoas.

Em geral, o tratamento dado ao transporte não motorizado (a pé e bicicleta) é insuficiente, reforçando uma lógica individual motorizada, com planejamento focado nos deslocamentos de veículos automotores. Quanto aos pedestres, são notadas menções genéricas à acessibilidade de portadores de necessidades especiais, em acordo com NBR 9050, porém os deslocamentos a pé claramente não são considerados prioridade. A bicicleta, por sua vez, não é tratada de maneira integrada aos outros modos de transporte, nem mesmo ao transporte público. Frequentemente, a bicicleta aparece como um tema vinculado à questão ambiental, em vez de ser considerada integrante do sistema de transportes do município.

Como ponto positivo, são notáveis as diretrizes para melhorar o transporte público coletivo, utilizando uma nova forma de sistema de transporte público atrelado à inclusão social. Inicia-se também a discussão do sistema de transporte local e as linhas intermunicipais, geridas por órgãos distintos, com conflitos na política tarifária, fixação dos itinerários de linhas e diferentes sistemas de bilhetagem. A análise de transportes e mobilidade nos PDM aponta para a necessidade de reforço esclarecimento de questões metropolitanas, e formulação de planos setoriais de mobilidade urbana.

Por sua vez, a questão Metropolitana nos PDM aponta na tendência de se privilegiar articulação vertical com a União e os Estados, em detrimento da articulação horizontal entre municípios. São feitas raras menções aos consórcios públicos intermunicipais para atacar as problemáticas como: abastecimento de água e esgoto, drenagem, tratamento de resíduos e sistemas de transporte, cujo tratamento metropolitano configura-se como um dos únicos modos efetivos de gestão e operação adequados, principalmente em municípios de menor porte sob área de conurbacão urbana. 
Com tantas limitações, a presença do enfoque Metropolitano nos PDM pode ser considerada frágil, indicando prevalecer uma expectativa de integração Metropolitana a partir da iniciativa da esfera Federal.

Quanto à efetivação do planejamento urbano participativo na perspectiva de gestão democrática das cidades, foram constatados inúmeros processos participativos nos PDM analisados. Porém, ainda é constatada insuficiência na participação popular, que por vezes é delegada a uma única audiência pública, com ausência de mecanismos para implantar medidas para o orçamento participativo da cidade.

Afinal, são vários os desafios para o fortalecimento do planejamento Urbano das cidades brasileiras. A dimensão do planejamento fiscal, o curto ciclo de gestão municipal e as dificuldades de financiar o desenvolvimento urbano apontam para o pragmatismo e imediatismo nas práticas de gestão urbana.

De acordo com os autores, o Planejamento Urbano requer atenção especial dos gestores, de modo a contribuir para o aproveitamento dos recursos públicos, maximização dos seus efeitos na cidade e redução dos déficits sociais e de infraestrutura urbana. Considerando que o PDM não é um plano de gestão, mas sim um plano da cidade e da sociedade, é necessária uma mudança cultural para superar práticas tecnocráticas na gestão urbana. Com a intensificação da disputa pelo mercado de terras e conflitos fundiários urbanos, o PDM deve propiciar a avaliação do acesso à terra urbanizada para o cumprimento da função social da propriedade, além de oferecer diálogo com serviços e equipamentos urbanos, de modo integrado às políticas urbanas.

São oferecidas recomendações aos gestores e à sociedade, além de ensinamentos fundamentais aos técnicos responsáveis pela elaboração de novos PDM, que tangem à estruturação de um sistema nacional de gestão democrática das cidades, estratégias de capacitação, cenários e alternativas de apoio aos pequenos municípios e fortalecimento do controle social no planejamento participativo. 
De forma otimista, mesmo com as dificuldades enfrentadas para implementação de princípios e diretrizes, que por sua vez são muito mais acessíveis em discurso do que em prática, o Estatuto da Cidade segue como uma norma fundamental de referência para a gestão das cidades e elaboração de planos e leis urbanísticas, fruto da busca por uma cidade com mais equidade e sustentabilidade.

Como importância de pesquisa, a identificação de limites e avanços dos instrumentos de planejamento e gestão urbana contribuem para concretização da proposta central do Estatuto da Cidade: o direito à cidade para toda a sociedade brasileira. Agora, caberia irmos além do discurso, e inserir a prática do ordenamento e desenvolvimento das funções sociais da cidade e da propriedade urbana. 